$4^{\text {th }}$ Brazilian Conference on Composite Materials. Rio de Janeiro, July $22^{\text {nd }}-25^{\text {th }}, 2018$

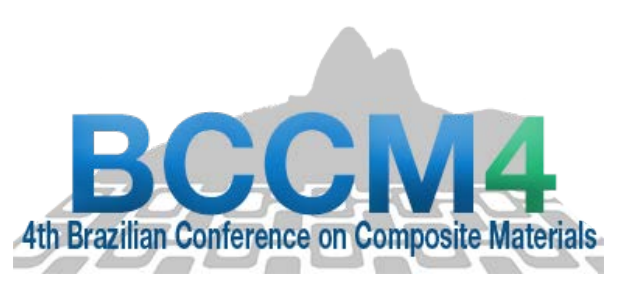

\title{
PREPARATION AND CHARACTERIZATION OF EXTRUDED PBAT/ORGANOCLAY FILMS
}

\author{
$\underline{\text { L.H. de Carvalho }}^{(1)}$, A.A. Nascimento Filho ${ }^{(1)}$
}

(1) Department Materials Science and Engineering, Federal University ofCampina Grande, Brazil

https://doi.org/10.21452/bccm4.2018.12.01

\begin{abstract}
Polymeric materials and their blends prepared from renewable and completely biodegradable resources are an important alternative to conventional synthetic materials. Produced by BASF, poly (butylene adipate) -co- (butylene terephthalate) (PBAT) commercially known as Ecoflex is a polymer with a good set of properties and low degradation during processing. The incorporation of additives, such as fillers, in plastics allows tailoring the properties of the polymer to specific applications and/or ease processing. In this paper, we investigate the influence of organoclay identity and content on the tensile properties, gas permeation characteristics and biodegradation of extruded PBAT/organophilic clay nanocomposite films. Cloisite C10A and C30B organoclays were used as fillers with loading levels of 0,1 and $3 \% \mathrm{w} / \mathrm{w}$. Processing was carried out in an internal mixer attached to a torque rheometer operating at 60rpm and 160 for $10 \mathrm{~min}$. Extruded flat films of the processed materials were obtained and their tensile properties were determined. Biodegradation was determined by weight loss as a function of burial time in fertile soil. Biocomposites degraded more slowly than the matrix, which was attributed to organoclay antimicrobial properties. Torque rheometry indicated more intense degradation on the biocomposites with higher organoclay content, particularly C30B. Although the influence of clay identity on the tensile properties of the films was minimal, their thickness increased and permeability and biodegradation decreased with clay content, particularly for C30B modified films.
\end{abstract}

\section{INTRODUCTION}

Easy moulding and innovation potential, low cost and low density are the reason plastic materials have been replacing traditional materials such as ceramic and metals. Polymeric materials as well as their blends and composites can be obtained as films, profiled sheets or shaped and/or blown artefacts, serving different segments of the industry, according to the characteristics required by each application [1]. 
The substitution of conventional plastics for other materials less aggressive to the environment, such as biodegradable polymers, is one of the solutions to reduce the time that polymer residues remain polluting and attacking the environment. Studies on the recycling of materials and the use of materials from renewable and / or biodegradable sources in the development of polymer products (composites or blends), especially for rapid disposal applications, are increasing and are being encouraged.

PHB (Poly (3-hydroxybutyric acid), Ecoflex TM (synthetic biodegradable polyester copolymer) and Ecobras TM (Ecoflex blend with thermoplastic starch) are examples of 100\% biodegradable systems classified as biopolymer (PHB), synthetic polymer (Ecoflex) or polymer blends (EcobrasTM). These three materials completely degrade, in a short time, by microbial attack (fungi, bacteria and enzymes) under appropriate conditions in the environment [2]. However, these three materials have the same problem: they tend to degrade during processing, compromising their mechanical properties and, consequently, their applications [3] .

The properties of plastics can be significantly altered by blending and by additive incorporation. Fillers, particularly mineral fillers, are often added to polymers to increase their mechanical, thermal and barrier properties. Nanofillers cause these same changes at low loading levels $(<10 \%)$ [4].

Considering the above, and that the packaging sector generates a large amount of plastic waste, responsible for environmental and visual pollution, the focus of this research lies in the development and characterization of flat films using a biodegradable polymer as the matrix and organoclays as fillers. The effect of clay identity and content on the mechanical properties, gas permeability and biodegradation of these systems are investigated, aiming to expand the range of possible applications of these films.

\section{EXPERIMENTAL}

\subsection{Materials}

The matrix employed was Ecoflex FC1200 manufactured by BASF. It is a synthetic aliphatic aromatic biodegradable copolyester which according to the manufacturer has a density of 1.26 $\mathrm{g} / \mathrm{cm}^{3}$ at ambient temperature, melt flow rate between 3 and $5 \mathrm{dg} / \mathrm{min}$ (ISO 1133, $190^{\circ} \mathrm{C} / 2,16$ $\mathrm{kg}$ ), glass transition temperature of $-30^{\circ} \mathrm{C}$, and melts at 110 to $120^{\circ} \mathrm{C}[5]$. DSC measurements in our lab indicate a slightly higher melting point (completing the melting process at $135^{\circ} \mathrm{C}$ ) and a low degree of crystallinity (10 to 15\%). Two organoclays were used as fillers: Cloisite C10A and Cloisite C30B. The structures of C10A and C30B organoclays are shown in Figure 1. d001 values for C10A and C30B organoclays are $1.92 \mathrm{~nm}$ and1.85nm, respectively and the fatty acids used (T in Figure 1) to modify both clays are composed of 65\% stearic acid (C18), 35\% palmitic acid (C16) and 5\% myristic acid (C14) [6].

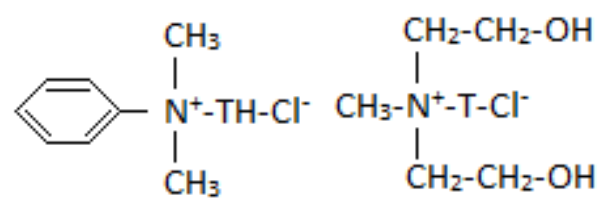

(a) (b)

Figure 1 - Chemical structures of (a) C10A and (b) C30B organoclays. 


\subsection{Methods}

Processing took place in a Rheomix 3000 internal mixer fitted with roller type rotors, attached to a ThermoScientific torque Rheometer. The mixer chamber is $310 \mathrm{~cm}^{3}$ and the fill factor used was $75 \%$. Operating conditions were: $60 \mathrm{rpm}, 160^{\circ} \mathrm{C}, 10 \mathrm{~min}$.

After processing the products were cooled to room temperature, ground and fed into an AXPlastics Lab16 chill-roll single screw extruder operating with a coat hanger die at $180^{\circ} \mathrm{C}, 45$ rpm and rollers at $26 \mathrm{rpm}$ and $15^{\circ} \mathrm{C}$ to generate flat films.

Tensile testing was performed on an EMIC DL-10000 apparatus operating with a $20 \mathrm{~N}$ cell at $50 \mathrm{~mm} / \mathrm{min}$ and room temperature. Samples were approximately $100 \times 10 \mathrm{~mm}^{2}$ and grip separation was $50 \mathrm{~mm}$.

Gas permeability tests were conducted on a Brugger GDP-C apparatus operating according to ASTM D 1434 standard at $25^{\circ} \mathrm{C}$. The film area was $78,4 \mathrm{~cm}^{2}$.

Biodegradation (biodisintegration) took place on simulated soil according to ASTM G-160-03 standard. 20x20x3mm compression molded samples were weighted and buried in soil placed in an oven maintained at $40-60 \%$ air humidity and $35^{\circ} \mathrm{C}$. Samples were removed from the soil cleaned, pat dried and weighted weekly and their weight loss reported as a function of time.

\section{RESULTS AND DISCUSSION}

Torque and temperature curves as a function of processing time are shown in Figure 2.
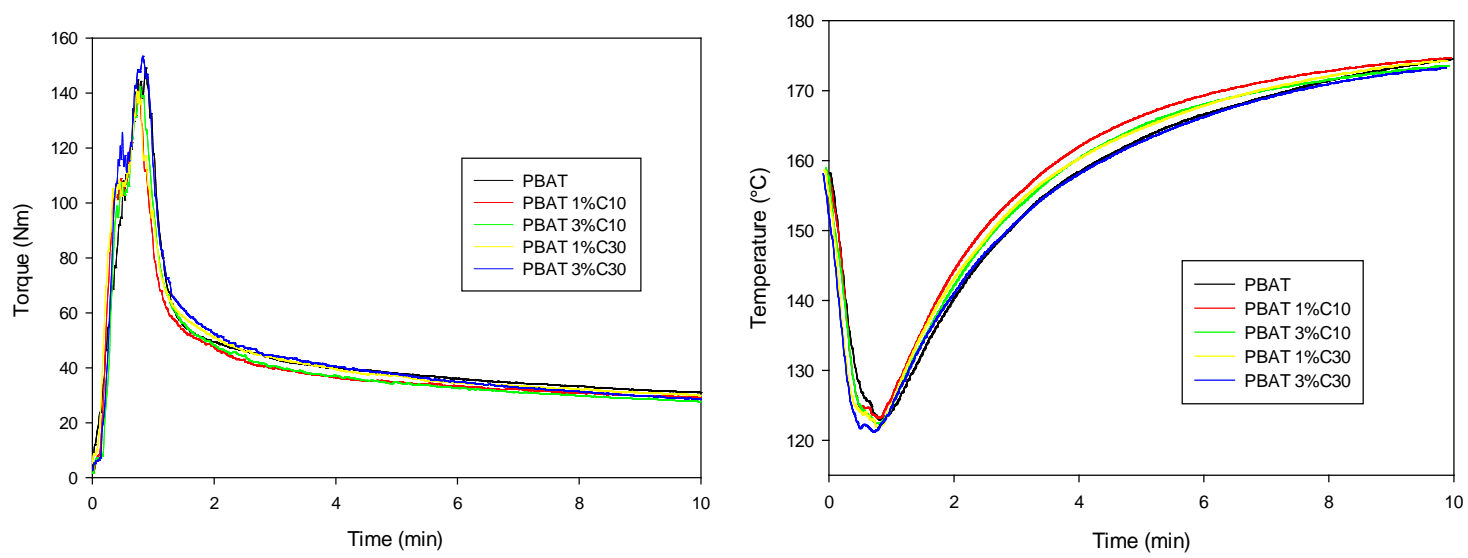

Figure 2 - Torque and temperature as a function of processing time in the internal mixer operating at $160^{\circ} \mathrm{C}$.

Temperature initially drops due to cold material feeding into the mixer and then increases by the combined effect of mechanical energy dissipation inside the chamber and heat transfer to/from the chamber wall. Torque increases by mechanical energy dissipation in the solids mix (friction and plastic deformation of the polymer particles), then decreases as the polymer melt. Polymer is molten after 4-5 min processing time. Neither torque nor temperature achieved a steady state plateau within the 10 min of processing employed here. Torque depends on polymer viscosity (and hence molecular weight) which strongly depends on temperature. Torque will decrease if polymers degrade during processing but it will also decrease if temperature rises. In order to eliminate 
temperature dependence on torque, the concept of adjusted torque (i.e., the torque expected for a given material to achieve at a fixed reference temperature) is used. A detailed description on the fundamentals of this concept is presented elsewhere [7-9]. Applying this concept one can estimate the influence of filler incorporation on the rate of degradation at the final stages (8-10 min) of processing. Table 1 shows the average torque, temperature and average adjusted torque at the final stages of processing as well as the rate of torque decrease $(\mathrm{dz} * / \mathrm{dt})$ and the \%rate of degradation $\mathrm{RZ} \%\left(\mathrm{dz} / \mathrm{z}^{*} \mathrm{dt} \mathrm{x} 100\right)$ of the systems investigated.

Table 1- Average toque, temperature, adjusted torque, torque decrease and \% rate of degradation at the final stage (8-10 $\mathrm{min})$ of processing as a function of film composition.

\begin{tabular}{|c|c|c|c|c|c|}
\hline COMPOSITION & Z $_{\text {AVG }}$ & TAVG $_{\text {AVG }}$ & Z $_{\text {AVG }}$ & DZ*/DT & RZ $\%^{*}$ \\
\hline PBAT & 31,99 & 173,20 & 50,89 & $-0,20$ & $-0,393$ \\
\hline PBAT 1\% C10A & 29,96 & 174,04 & 48,44 & $-0,40$ & $-0,826$ \\
\hline PBAT 3\% C10A & 28,73 & 172,95 & 45,45 & $-0,66$ & $-1,442$ \\
\hline PBAT 1\% C30B & 31,01 & 173,70 & 49,81 & $-0,50$ & $-1,002$ \\
\hline PBAT 3\% C30B & 29,84 & 172,72 & 46,99 & $-1,02$ & $-2,162$ \\
\hline
\end{tabular}

The data indicates that torque slightly decreases with filler incorporation, content and identity at the final stages of processing. This means that PBAT and its compounds, albeit not strongly, degrade during processing and that degradation is higher for C30B composites with higher filler content. It is believed that this results from the more polar structure of the C30B organoclay.

CO2 gas permeability data for the films investigated are reported in Table 2.

Table 2- CO2 gas permeability of PBAT and its nanocomposites processed at $160^{\circ} \mathrm{C}$.

\begin{tabular}{|c|c|c|}
\hline Film & $\begin{array}{c}\text { Thickness } \\
\text { ( } \mu \mathrm{m})\end{array}$ & $\begin{array}{c}\text { Permeability } \\
\left(10^{-6} \mathrm{~cm}^{3} \mathrm{STP} / \mathrm{cm}-\mathrm{h}-\mathrm{bar}\right)\end{array}$ \\
\hline PBAT & $110 \pm 21,6$ & $688 \pm 40$ \\
\hline $\begin{array}{c}\text { 1C10A } \\
160\end{array}$ & $190 \pm 16,3$ & $195,1 \pm 13,6$ \\
\hline $\begin{array}{c}\text { 3C10A } \\
160\end{array}$ & $143,3 \pm 4,7$ & $136 \pm 21$ \\
\hline $\begin{array}{c}1 \mathrm{C} 30 \mathrm{~B} \\
160\end{array}$ & $192,5 \pm 7,5$ & $92,3 \pm 19,5$ \\
\hline $\begin{array}{c}\text { 3C30B } \\
160\end{array}$ & $191,7 \pm 11,8$ & $88 \pm 14,4$ \\
\hline
\end{tabular}

As expected, the presence and concentration organoclay reduced film permeability, as fillers increase gas path tortuosity. Filler identity also seemed to play a role in this decrease as lower gas permeability was achieved with C30B modified films. It is likely that the somewhat more polar structure of the C30B clay has promoted a better interaction, dispersion or exfoliation of this filler, reducing the permeability of PBAT/C30B systems when compared to PBAT/C10A systems. XRD, SEM and MET analyses are necessary to confirm this hypothesis. Nonetheless, the addition of organophilic clay reduced the permeability of the systems to values comparable to those of premium packaging films (HDPE, LLDPE), which are much lower than the common LDPE film [10]. Biodegradation results are shown in Figure 3. 


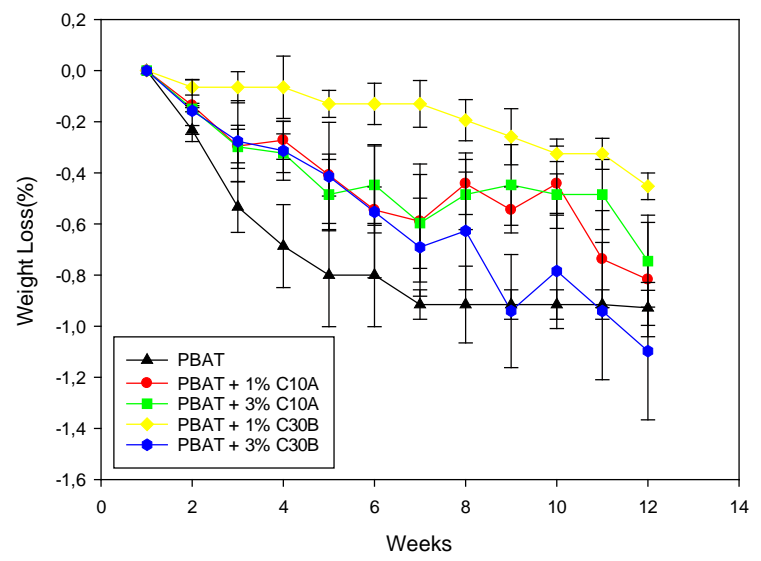

Figure 3 - Biodegradation of PBAT and PBAT/organoclay films.

Unexpectedly, biodegradation of all systems under investigation was very low $(<1,5 \%)$ in the 12 weeks of the experiment. PBAT is reported to be $100 \%$ biodegradable polymer. Indeed, we have shown that if the polymer is UV exposed for as little as 5 days, it biodegrades in a few weeks and, if exposed for 20 days it disintegrates within one week, which indicates that it biodegrades very fast provided it is pre-oxidized[11]. The data also indicates that clay incorporation, particularly $1 \%$ C30B. This behavior was associated with possible antimicrobial characteristics of organoclays[12-13].

The tensile properties of some of the films investigated are displayed in Table 3.

Table 3 - Tensile properties of PBAT/organoclay films

\begin{tabular}{|c|c|c|c|}
\hline & $\boldsymbol{\varepsilon}$ & $\boldsymbol{\sigma}_{\max }$ & $\mathbf{E}$ \\
$\mathbf{( \% )}$ & $\mathbf{M P a}$ & $\mathbf{M P a}$ \\
\hline PBAT & $621,9 \pm 56,13$ & $13,2 \pm 1,75$ & $95,79 \pm 3,37$ \\
\hline 3C10A 160 & $666,70 \pm 66,43$ & $12,56 \pm 1,31$ & $179,77 \pm 31,84$ \\
\hline 3C30B 160 & $717,70 \pm 63,77$ & $16,27 \pm 1,48$ & $140,16 \pm 3,55$ \\
\hline
\end{tabular}

As expected, organoclay incorporation caused an increase in the elastic modulus of PBAT films. Elongation at break and maximum tensile strength seem to be a little higher for the systems containing C30B organoclay. These increases, however, are within experimental error and further work needs to be done before conclusions can be made. The available data only allows one to state that organoclay incorporation led to stiffer materials with strength and deformations comparable to that of the neat polymer.

\section{CONCLUSIONS}

Results showed that, although degradation during processing was minimal, it slightly increased with organoclay incorporation. Our data also indicated that this degradation increases with the content and identity of the organophilic clay, being higher in the systems containing the C30B clay. It is believed that the somewhat more polar structure of this clay is responsible for this behavior. Extruded PBAT and PBAT/organoclay flilms were obtained and their thickness increases with clay content and identity, being larger for the PBAT/C30B system. Nanoclay 
incorporation led to stiffer films with elongation at break and tensile strength similar to that of neat PBAT. The biodegradation of non-oxidized systems was quite low $(<1.5 \%)$ and organoclay incorporation seemed to slow down biodegradation, which might be associated with antimicrobial activity of these clays. CO2 permeability of the nanocomposites was significantly smaller for the nanocomposites and that it was lower for PBAT/C30B systems. It is believed that this clay promotes better filler/matrix interaction. The low CO2 permeability of the nanocomposites recommends these materials for food packaging, where this property is a major concern. The permeability of PBAT/C10A and PBAT/C30B films are close to those of the materials ideal for this application, with the advantage of being fully biodegradable and processable by conventional methods.

\section{ACKNOWLEDGEMENTS}

The financial support of CNPq (grant \#473622/2015-00 and Dr. Carvalho's research fellowship) and CAPES (PNPD fellowship of Dr. Morais) are acknowledged.

\section{REFERENCES}

[1] Bastioli C (ed) - Handbook of biodegradable polymers, 2nd edn. Smithers Rapra Technology, Shawbury (2014).

[2] Mondal D, Bhowmick B, Maity D, Mollick MR, Rana D, Rangarajan V, Sen R, Chattopadhyay D - Investigation on sodium benzoate release from poly(butylene adipate-coterephthalate)/organoclay/sodium benzoate based nanocomposite film and their antimicrobial activity. J Food Sci 80(2015) E602-E609.

[3] Ebnesajjad S (ed) - Handbook of biopolymers and biodegradable plastics. properties, processing (2013).

and applications. Elsevier, Amsterdam

[4] Utracki LA - Clay-containing polymeric nanocomposites. Rapra Technology, Sawbury (2004).

[5] BASF, A. G. Ecoflex ${ }^{\circledR}$ : biodegradable plastic. basf plastics - aplications, range, properties, processing (2003).

[6] Rhim JW, Park HM, Ha CS (2013) Bio-nanocomposites for food packaging applications. Progress in Polymer Science. 38,(2013),1629-1652

[7] Costa ARM, Almeida TG, Silva SML, Carvalho LH, Canedo EL - Chain extension in poly(butylene adipate-co-terephthalate). Inline analysis in a laboratory internal mixer. Polym Test 42, (2015), 115-121.

[8] Alves TS, Neto JES, Silva SML, Carvalho LH, Canedo EL - Process simulation of laboratory internal mixers. Polym Test 50 (2016), 94-100.

[9] Almeida TG, Neto JES, Costa ARM, da Silva AS, Carvalho LH, Canedo EL (2016) Degradation during processing in poly(butylene adipate-co-terephthalate)/vegetable fiber compounds estimated by torque rheometry. Polym Test 55:204-211.

[10] Van Krevelen DW, Te Nijenhuis K - Properties of polymers, 4th edn. Elsevier, Amsterdam (2009).

[11] Falcão GAM, Vitorino MBC, Almeida TG, Bardi MAG, Carvalho LH, Canedo EL PBAT/organoclay composite films: preparation and properties, Pym. Bull 74, (2017),4423-4434.

[12] KHOSRAVI-DARANI K and BUCCI DZ - Application of Poly(hydroxyalkanoate)..., Chem. Biochem. Eng. Q., 29 (2) 275-285 (2015); 
[13] Moustafa H, El Kissi N, Abou-Kandil AI, Abdel-Aziz MS, Dufresne A - PLA/PBAT Bionanocomposites with Antimicrobial Natural Rosin for Green packaging - ACS Appl. Mater. Interfaces 9 (23) (2017) 20132-20141. 